\title{
Note: Thermal Analog to Atomic Force Microscopy Force- Displacement Measurements for Nanoscale Interfacial Contact Resistance
}

\author{
Brian D. Iverson \\ Brigham Young University - Provo, bdiverson@byu.edu \\ John E. Blendell \\ Suresh V. Garimella
}

Follow this and additional works at: https://scholarsarchive.byu.edu/facpub

Part of the Mechanical Engineering Commons

\section{Original Publication Citation}

Iverson, B. D., Blendell, J. E., and Garimella, S. V., 2010, "Note: Thermal analog to atomic force microscopy force-displacement measurements for nanoscale interfacial contact resistance," Review of Scientific Instruments, Vol. 81. DOI: 10.1063/1.3361157

\section{BYU ScholarsArchive Citation}

Iverson, Brian D.; Blendell, John E.; and Garimella, Suresh V., "Note: Thermal Analog to Atomic Force Microscopy Force-Displacement Measurements for Nanoscale Interfacial Contact Resistance" (2010). Faculty Publications. 2972.

https://scholarsarchive.byu.edu/facpub/2972

This Peer-Reviewed Article is brought to you for free and open access by BYU ScholarsArchive. It has been accepted for inclusion in Faculty Publications by an authorized administrator of BYU ScholarsArchive. For more information, please contact ellen_amatangelo@byu.edu. 


\section{Note: Thermal analog to atomic force microscopy force-displacement measurements for nanoscale interfacial contact resistance}

Cite as: Rev. Sci. Instrum. 81, 036111 (2010); https://doi.org/10.1063/1.3361157

Submitted: 26 September 2009 . Accepted: 22 February 2010 . Published Online: 31 March 2010

Brian D. Iverson, John E. Blendell, and Suresh V. Garimella

\section{ARTICLES YOU MAY BE INTERESTED IN}

Atomic force microscope infrared spectroscopy on $15 \mathrm{~nm}$ scale polymer nanostructures Review of Scientific Instruments 84, 023709 (2013); https://doi.org/10.1063/1.4793229

Self-heating in piezoresistive cantilevers

Applied Physics Letters 98, 223103 (2011); https://doi.org/10.1063/1.3595485

Theory of infrared nanospectroscopy by photothermal induced resonance Journal of Applied Physics 107, 124519 (2010); https://doi.org/10.1063/1.3429214

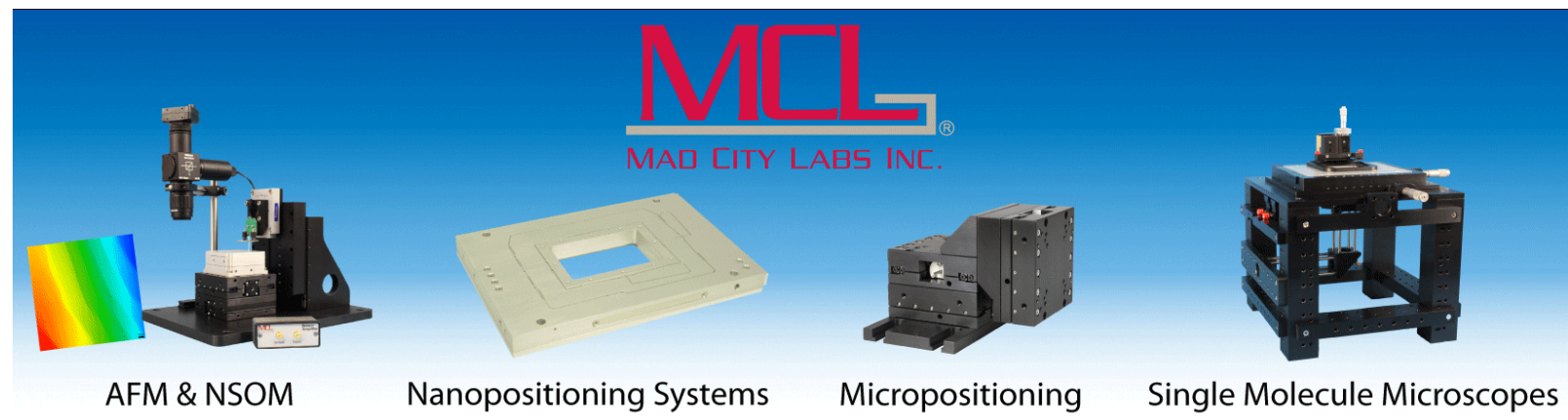




\title{
Note: Thermal analog to atomic force microscopy force-displacement measurements for nanoscale interfacial contact resistance
}

\author{
Brian D. Iverson, ${ }^{1,2,3}$ John E. Blendell, ${ }^{3,4, a)}$ and Suresh V. Garimella ${ }^{2,3}$ \\ ${ }^{1}$ Sandia National Laboratories, Albuquerque, New Mexico 87185, USA \\ ${ }^{2}$ School of Mechanical Engineering, Purdue University, West Lafayette, Indiana 47907, USA \\ ${ }^{3}$ Birck Nanotechnology Center, Purdue University, West Lafayette, Indiana 47907, USA \\ ${ }^{4}$ School of Materials Engineering, Purdue University, West Lafayette, Indiana 47907, USA
}

(Received 26 September 2009; accepted 22 February 2010; published online 31 March 2010)

\begin{abstract}
Thermal diffusion measurements on polymethylmethacrylate-coated Si substrates using heated atomic force microscopy tips were performed to determine the contact resistance between an organic thin film and $\mathrm{Si}$. The measurement methodology presented demonstrates how the thermal contrast signal obtained during a force-displacement ramp is used to quantify the resistance to heat transfer through an internal interface. The results also delineate the interrogation thickness beyond which thermal diffusion in the organic thin film is not affected appreciably by the underlying substrate. (C) 2010 American Institute of Physics. [doi:10.1063/1.3361157]
\end{abstract}

Interfaces between mating parts or dissimilar materials introduce thermal resistance to heat flow due to partial surface contact. One-dimensional reference bar experiments are commonly used to quantify area-averaged contact resistance across interfaces. ${ }^{1}$ However, this averaging does not provide local information for individual asperities and is generally limited to thick samples in order to accommodate temperature measurement. Organic materials are commonly used as a filler to increase the contact area between mating surfaces and often serve as a matrix for dispersion of higherconductivity materials (such as metal particulates, carbon nanotubes, etc.) to further decrease contact resistance. While thermal conductivity of thin-film resists has been studied, contact resistance between these thin films and substrates is a lingering challenge. ${ }^{2}$

In order to characterize local thermal resistance across thin films and interfaces, the atomic force microscopy (AFM) calibration technique known as a force-displacement ramp is used with heated AFM tips that can simultaneously detect changes in temperature. Heated cantilever tips are commonly used in scanning thermal microscopy or local thermal analysis and provide resolution on the order of the tip, typically tens of nanometers. ${ }^{3,4}$ Calibration of the thermal behavior of heated cantilevers has been studied, ${ }^{5,6}$ allowing these sensing tools to be used for material-property measurement and characterization. ${ }^{7,8}$ Early application of these tools includes subsurface detection. ${ }^{9,10}$ Models of scanning force microscopy resolution depth have also been presented. ${ }^{11}$ Force-displacement experiments have been used as a method for quantifying contact potential between a cantilever and a surface as a function of temperature. ${ }^{12}$ Of particular note, Park et al. ${ }^{13}$ demonstrated that bringing a heated cantilever tip in and out of contact with a surface provides a measurable change in tip thermal diffusion. We exploit this observed change in thermal diffusion to estimate contact resistance at

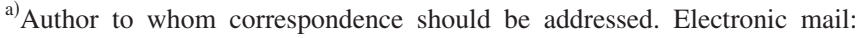
blendell@purdue.edu.
}

Si/organic interfaces using thin-film polymethylmethacrylate (PMMA).

During force-displacement curve calibration, the cantilever experiences multiple stages as the cantilever ramps toward the surface, snaps into contact, bends, and then straightens again as the cantilever moves away from the surface until it suddenly releases from surface contact [see Figs. 1 and 2(a)]. The AFM cantilevers used in this work incorporate a Wheatstone bridge for heat generation at the tip and temperature sensing (Anasys Instruments model GLA). One resistor of the bridge is a metal strip along the cantilever tip (40 nm thick Pd trace shown in Fig. 1), which heats as current flows and also provides a temperature-dependent resistance used for sensing thermal changes as the tip comes in contact with surfaces. With a heated cantilever tip and a cool substrate, imbalance in the Wheatstone bridge is detected in the thermal-displacement curve [Fig. 2(b)]. First, the voltage decreases due to a decrease in resistance to heat flow through a thinning air gap between cantilever and substrate. Once snap-in occurs, a significant change in voltage imbalance is detected as conduction from tip to substrate increases and heat transfer is no longer hindered by a low-conductivity air gap. This abrupt change in voltage is dependent on the thermal diffusivity of the substrate in addition to tip heating conditions [Fig. 2(b)] and is the primary measurement used in quantifying the resistance to thermal diffusion in this work. Thermal diffusion is considered steady since the time the tip $(D \approx 150 \mathrm{~nm}$ diameter) is in contact with the sample is determined to be more than six orders of magnitude larger than the characteristic time $\left(D^{2} / \alpha\right)$ appearing in the Fourier number for heat conduction. Figure 2(c) illustrates the resistances to heat transfer between the cantilever and a Si substrate.

With the ability to distinguish thermal properties of a probed surface, an organic layer was included in an effort to measure the contact resistance between PMMA and $\mathrm{Si}\left[R_{\mathrm{Si} / O}\right.$, Fig. 2(d)]. However, resistance associated with thermal diffusion through the organic thin film $\left(R_{\mathrm{O}}\right)$ would also be present. By using thinned PMMA layers that approach zero thickness, the difference between the sum of the resistances 

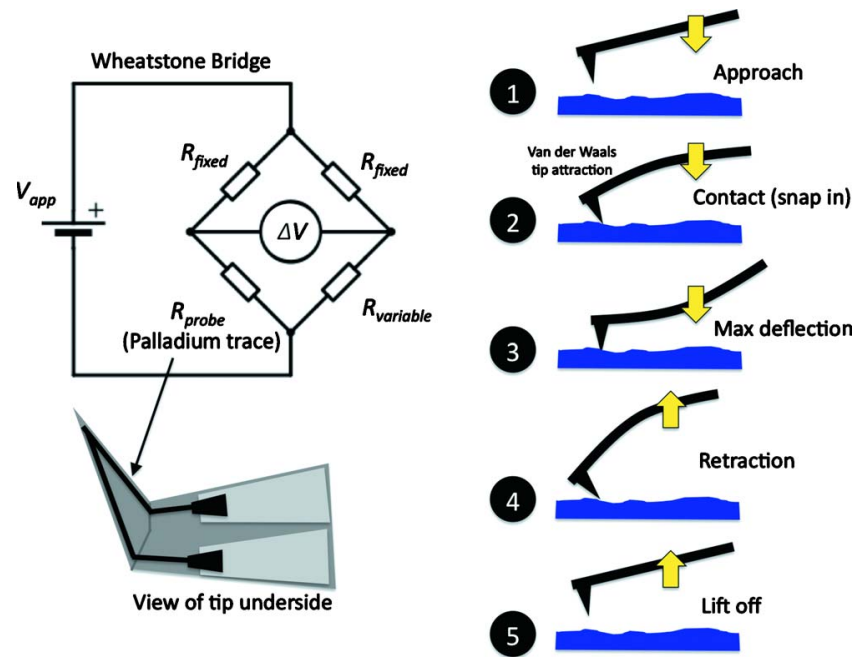

FIG. 1. (Color online) Illustration of the sensing mechanism integrated with the probe tip along with a representation of tip approach and retraction during interrogation (numbering corresponds with Fig. 2).

shown in Figs. 2(c) and 2(d) approaches the interface contact resistance $R_{\mathrm{Si} / O}$. A series of Si substrates with PMMA films of varying thickness was prepared by spinning Microchem 950 (PMMA A4) on polished $\mathrm{Si}(<5 \mathrm{~nm}$ roughness). In order to span a range of thicknesses, Microchem 950 was diluted with anisole in ratios of $1: 1$ and $1: 1.5$ and stirred for 90 $\min$ at $600 \mathrm{rpm}$. The solutions were spun on at varying speeds (typically 500-5000 rpm) for $40 \mathrm{~s}$ yielding thicknesses from $40-720 \mathrm{~nm}$, as measured using an AFM. The PMMA films were then heated in air at $180^{\circ} \mathrm{C}$ for $90 \mathrm{~s}$, and then at $140{ }^{\circ} \mathrm{C}$ for $1 \mathrm{~h}$.

Using the heated AFM tip, a series of thermal forcedisplacement measurements at various applied tip voltages

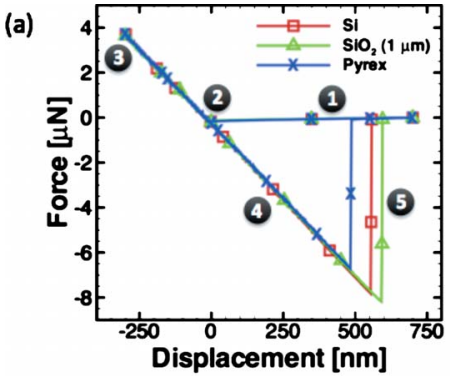

(c)

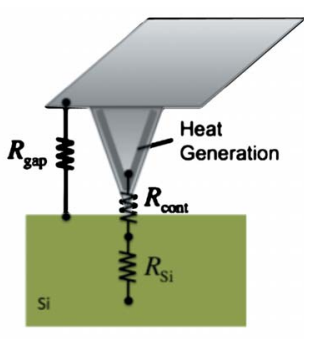

(b)

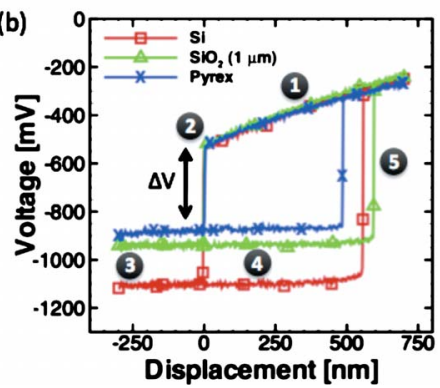

(d)

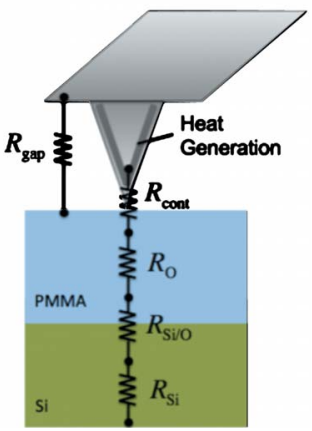

FIG. 2. (Color online) Representative force-displacement measurement illustrating the (a) force and corresponding (b) thermal response of the cantilever during a displacement ramp for three substrates of different thermal conductivity (numbering corresponds with Fig. 1). Resistance to heat transfer between heated cantilever and (c) Si substrate, and (d) Si substrate coated with an organic thin film.

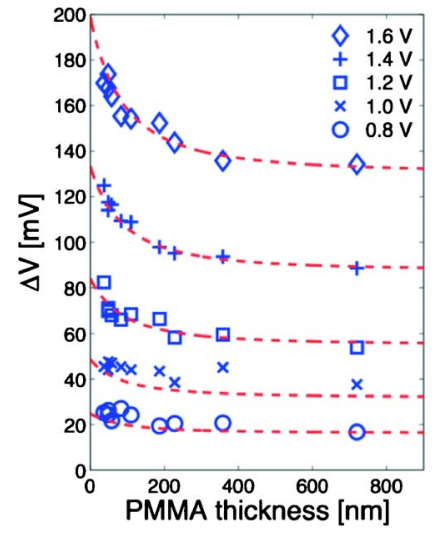

(a)

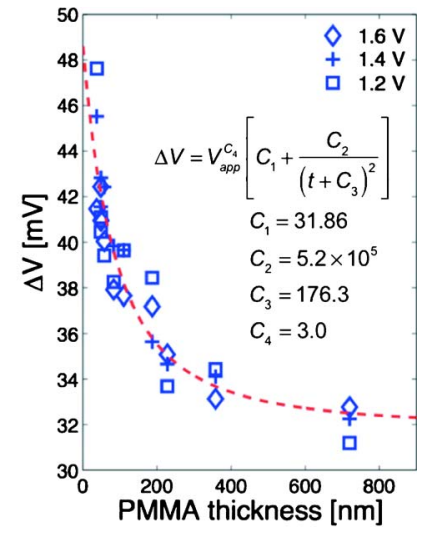

(b)
FIG. 3. (Color online) Thermal contrast during force-displacement ramp (a) as a function of varying PMMA thicknesses for various applied voltages and (b) reduced data for $1.2,1.4$, and $1.6 \mathrm{~V}$ with curve fit parameters.

$\left(V_{\text {app }}\right)$ was performed. Thermal contrast measurements, obtained as a change in Wheatstone bridge voltage for the tip in and out of contact with the substrates during the approach ramp $[\Delta V$, Fig. 2(b)], were obtained for each PMMA-coated sample. Similar experiments were performed on uncoated $\mathrm{Si}$. The resulting $\Delta V$ is plotted in Fig. 3(a) as a function of PMMA thickness. First, it is apparent that for PMMA thicknesses above $\sim 300 \mathrm{~nm}$, there is a little change in the thermal contrast. In this range, the heat transferred from tip to substrate approaches the behavior of bulk PMMA and provides an upper limit to the interrogation thickness for measuring resistance to diffusion under the PMMA layer. For higher thermal-conductivity films, we anticipate larger interrogation thicknesses. Second, a dramatic increase in the thermal signal is observed with reducing PMMA thickness (below the maximum interrogation thickness) for higher applied voltages. For lower applied voltages $(0.8$ and $1.0 \mathrm{~V})$, the amount of heat available for dissipation is reduced, and hence the maximum interrogation thickness is approached at smaller film thicknesses, making this $\Delta V$ less pronounced.

However, there is a marked difference between the measurements for the thinnest PMMA layers [Fig. 3(a)] and the $\Delta V$ measured for uncoated Si. This difference results from the interface contact resistance $R_{\mathrm{Si} / \mathrm{O}}$. The data obtained for bridge voltages of 1.2-1.6 V were fitted in order to obtain the y-intercept for the limiting PMMA thickness, as shown in Fig. 3(b). The $\Delta V$ values reduce to a single line by scaling the measurement by the bridge voltage and the inverse of the film thickness. The resulting curve-fit equation and constants are provided in Fig. 3(b) and are plotted as the dashed line in Figs. 3(a) and 3(b). The curve fit has an average error of $2.9 \%$ and a maximum error of $9.7 \%$.

The intercept for reducing PMMA thickness $\left[\Delta V_{\text {intercept }}\right.$, Fig. 3(b)] and the $\Delta V$ measured on uncoated $\mathrm{Si}\left(\Delta V_{\mathrm{Si}}\right)$ is plotted in Fig. 4(a) as a function of the applied voltage. The difference between $\Delta V_{\mathrm{Si}}$ and $\Delta V_{\text {intercept }}$ represents the interfacial contribution to thermal resistance $R_{\mathrm{S} / / \mathrm{O}}$. The $\Delta V_{\mathrm{Si}}$ data points for $0.8,1.2$, and $1.6 \mathrm{~V}$ in Fig. 4(a) are an average of eight data points taken at $500 \mathrm{~nm}$ spacing increments on Si. The standard deviations of these measurements divided by the average of the measurements are $6.4 \%, 2.9 \%$, and $1.4 \%$, 


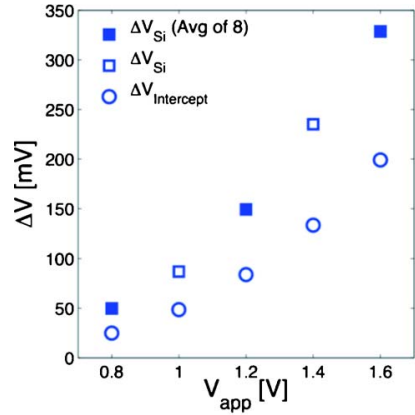

(a)

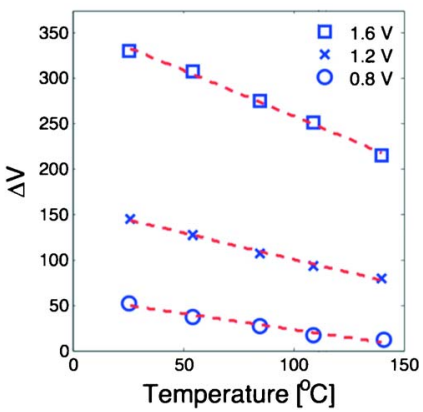

(b)
FIG. 4. (Color online) (a) Thermal contrast during force-displacement ramp as a function of the applied voltage for experiments on $\mathrm{Si}$ and the curve-fit y-intercept from Fig. 3 (filled markers represent an average of eight measurements at $500 \mathrm{~nm}$ spacing increments) and (b) thermal contrast during force-displacement ramp as a function of the Si surface temperature.

respectively. This highlights the measurement repeatability and indicates that measurement error in $\Delta V$ is less than $10 \%$.

The interfacial resistance was calibrated by relating $\Delta V$ to the temperature change in the tip. A heated stage with a thin-film polyimide heater (Minco) was mounted between $\mathrm{Si}$ (500 $\mathrm{nm}$ thick) and an insulating foam pad $(\sim 3 \mathrm{~mm})$. The stack was bonded using Duralco 132 thermal epoxy (Cotronics) with a thermocouple attached to the top surface of the Si. Thermal force-displacement curves were measured over a temperature range from 25 to $150^{\circ} \mathrm{C}$. Figure 4(b) illustrates the measured thermal contrast, normalized by the $\Delta V$ obtained at room temperature $\left(\Delta V_{0}\right)$, as a function of the heated $\mathrm{Si}$ surface temperature for three applied voltages. The $\Delta V$ decreases linearly with increase in temperature with slopes of $0.36,0.58$, and 1.01 for $0.8,1.2$, and $1.6 \mathrm{~V}$, respectively.

The tip heating is a function of the temperaturedependent resistance and the voltage drop across the tip resistor. The tip resistance was recorded for every measurement of Fig. 3; average values are provided in Table I and vary less than $1 \%$ from the measured value. The calculated Joule heating for the applied voltages considered here is in the range of $0.12-0.50 \mathrm{~mW}$ (Table I).

To estimate the contact resistance between the PMMA and $\mathrm{Si}$, all the heat transferred from tip to substrate is as-

TABLE I. Tip heating conditions for applied voltages in the range of $0.8-1.6 \mathrm{~V}$.

\begin{tabular}{ccccc}
\hline $\begin{array}{c}\text { Applied } \\
\text { voltage } \\
(\mathrm{V})\end{array}$ & $\begin{array}{c}\text { Tip } \\
\text { resistance } \\
(\Omega)\end{array}$ & $\begin{array}{c}\text { Tip voltage } \\
\text { drop } \\
(\mathrm{V})\end{array}$ & $\begin{array}{c}\text { Tip } \\
\text { heating } \\
(\mathrm{mW})\end{array}$ & $\begin{array}{c}\text { Contact } \\
\text { resistance } \\
\left(\mathrm{m}^{2} \mathrm{~K} / \mathrm{W}\right)\end{array}$ \\
\hline 0.8 & 351.5 & 0.21 & 0.12 & $4.01 \times 10^{-8}$ \\
1.0 & 355.4 & 0.26 & 0.19 & $2.90 \times 10^{-8}$ \\
1.2 & 359.0 & 0.32 & 0.28 & $2.86 \times 10^{-8}$ \\
1.4 & 362.0 & 0.37 & 0.38 & $2.32 \times 10^{-8}$ \\
1.6 & 365.5 & 0.42 & 0.50 & $1.81 \times 10^{-8}$ \\
\hline \hline
\end{tabular}

sumed to cross the $\mathrm{Si} /$ organic interface. In this manner, the resistance can be calculated as $R_{\mathrm{S} / \mathrm{O}}^{\prime \prime}=\Delta T / q^{\prime \prime}$. Park et al. ${ }^{13}$ showed that approximately $25 \%$ of the heat generated in the cantilever tip is transferred to the substrate through the tip contact. Despite the differences in cantilever geometry, we assume the same fractional amount of heat transfer from tip to substrate to provide a quantitative estimate of contact resistance. Analysis of heat transferred across the gap and through the tip is the subject of future work to be performed through modeling and experimental analysis. A $150 \mathrm{~nm}$ tip diameter is assumed to approximate the contact area. Converting the measured $\Delta V_{\mathrm{Si}}-\Delta V_{\text {intercept }}$ (Si/organic contact resistance contribution to the thermal contrast) to $\Delta T$ using the slope of the curve fits in Fig. 4(b) (and estimating the slope for 1.0 and $1.4 \mathrm{~V}$ using a linear fit), we can calculate the interface contact resistance in terms of a temperature difference. Using $25 \%$ of the generated heat, the contact resistance for the $\mathrm{Si} /$ organic contact resistance is calculated to be 1.8 $\times 10^{-8}$ to $4.0 \times 10^{-8} \mathrm{~m}^{2} \mathrm{~K} / \mathrm{W}$ (Table I). This is $2-5$ times smaller than the lower range of contact resistances reported for an $\mathrm{Al} / \mathrm{Al}$ interface with a $\mathrm{Pb}$ coating. ${ }^{14}$

This paper demonstrates the feasibility of using heated AFM tips to quantify the contact resistance between thin films and underlying substrates. The thermal contrast signal measured during force-displacement ramping is demonstrated to be a useful thermal measurement technique. Further, we show that there is a limit to the thickness of the film for characterization using thermal diffusion above which the impact of the underlying substrate diffusivity is not discernible. This technique is capable of spatial resolution on the order of the AFM tip radius, making small-scale defect detection possible.

${ }^{1}$ V. Singhal, P. J. Litke, A. F. Black, and S. V. Garimella, Int. J. Heat Mass Transfer 48, 5446 (2005).

${ }^{2}$ D. Chu, M. Touzelbaev, K. E. Goodson, S. Babin, and R. F. Pease, J. Vac. Sci. Technol. B 19, 2874 (2001).

${ }^{3}$ A. Majumdar, Annu. Rev. Mater. Sci. 29, 505 (1999).

${ }^{4}$ G. Meyers, A. Pastzor, Jr., and K. Kjoller, Am. Lab. (Shelton, Conn.) 39, 9 (2007).

${ }^{5}$ B. W. Chui, T. D. Stowe, Y. S. Ju, K. E. Goodson, T. W. Kenny, H. J. Mamin, B. D. Terris, R. P. Ried, and D. Rugar, J. Microelectromech. Syst. 7, 69 (1998).

${ }^{6}$ J. Lee, T. Beechem, T. L. Wright, B. A. Nelson, S. Graham, and W. P. King, J. Microelectromech. Syst. 15, 1644 (2006).

${ }^{7}$ S. Lefèvre, S. Volz, J.-B. Saulnier, C. Fuentes, and N. Trannoy, Rev. Sci. Instrum. 74, 2418 (2003).

${ }^{8}$ B. A. Nelson and W. P. King, Rev. Sci. Instrum. 78, 023702 (2007)

${ }^{9}$ A. Hammiche, H. M. Pollock, M. Song, and D. J. Hourston, Meas. Sci. Technol. 7, 142 (1996).

${ }^{10}$ A. Hammiche, D. J. Hourston, H. M. Pollock, M. Reading, and M. Song, J. Vac. Sci. Technol. B 14, 1486 (1996).

${ }^{11}$ L. David, S. Gomes, and M. Raynaud, J. Phys. D 40, 4337 (2007).

${ }^{12}$ J. L. Remmert, Y. Wu, J. Lee, M. A. Shannon, and W. P. King, Appl. Phys. Lett. 91, 143111 (2007).

${ }^{13}$ K. Park, G. L. W. Cross, Z. M. Zhang, and W. P. King, ASME Trans. J. Heat Transfer 130, 102401 (2008).

${ }^{14}$ F. P. Incropera, D. P. DeWitt, T. L. Bergman, and A. S. Lavine, Fundamentals of Heat and Mass Transfer, 6th ed. (Wiley, New York, 2007). 